\title{
The Dimensional Hematological Alterations Induced in Blood of Rats In vivo by Intraperitoneal Administration of Gold Nanoparticles
}

\author{
Mohamed Anwar K Abdelhalim ${ }^{1 *}$ and Sherif A. Abdelmottaleb Moussa ${ }^{2}$
}

${ }^{1}$ Department of Physics and Astronomy, College of Science, King Saud University, Saudi Arabia

${ }^{2}$ Department of Physics, College of Science, Al-Imam Muhammad Ibn Saud Islamic University, P.O. Box 90950, Riyadh, 11623, Saudi Arabia

\begin{abstract}
Background: The aim of the present study was to investigate the effects of intraperitoneal administration of (Gold Nanoparticles) GNPs on the dimensional hematological alterations in rats in an attempt to cover and understand the toxicity and the potential role of GNPs as a therapeutic and diagnostic tool.

Methods: A total of 30 healthy male Wistar-Kyoto rats were used in this study. Animals were randomly divided into groups, 2 GNPs-treated rats groups and one control group (NG). 2 GNPs-treated G1 and G2; received intraperitoneal administration of $50 \mu \mathrm{l}$ of 10 and $50 \mathrm{~nm}$ GNPs for a period of 3 days. Hematological parameters were measured using standard hematological techniques.

Results: The decrease in White Blood Cells (WBCs), Red Blood Cells (RBCs) count, monocytes\%, neutrophils\% and eosinophils\%, observed with $10 \mathrm{~nm}$ GNPs was significantly higher than $50 \mathrm{~nm}$ GNPs and control. The lymphocytes\% with $10 \mathrm{~nm}$ GNPs significantly increased compared with $50 \mathrm{~nm}$ GNPs and control. The Hemoglobin (HB) level, Hematocrit (HCT)\%, Mean Corpuscular Volume (MCV), Mean Corpuscular Hemoglobin (MCH), Mean Corpuscular Hemoglobin Concentration (MCHC) and Platelets (PLTs) count increased after administration of 10 and 50 nm GNPs compared with the control. The Mean Platelet Volume (MPV), Plateletcrit (PCT) and Platelet Distribution Width (PDW) significantly decreased with $50 \mathrm{~nm}$ GNPs compared with $10 \mathrm{~nm}$ GNPs and control; while Mean Corpuscular Volume (MCV) significantly increased with $50 \mathrm{~nm}$ GNPs. The Red blood cell Distribution Width (RDW) induced non-significant increase compared with the control.

Conclusions: The decrease in RBCs count might be due to the destruction of RBCs. The increase in Hematocrit $(\mathrm{HCT}) \%$ might be due to an increase in RBCs volume. The changes in RBCs indicates changes in morphology and deformability of RBCs, which confirmed by a slightly increase in RDW\%. The significant increase in PLTs count might lead to thrombosis or aggregation of blood vessels.
\end{abstract}

Keywords: Gold nanoparticles; MCV; MCH; MCHC; MPV; PCT\%; PDW\%

\section{Introduction}

The wide spread use of Gold Nanoparticles (GNPs) in biological applications has been due to their simple synthesis methods [1], ease of surface modification with peptides, DNA and antibodies [2-4] and unique physicochemical properties such as excellent absorbance and scattering of light. On the basis of these properties, GNPs have important applications for biological diagnostics [5] cell labeling [6] targeted drug delivery [7] medical imaging [8] cancer therapy [9-12].

NPs (Nanoparticles) can potentially cause adverse effects on organ, tissue, cellular, subcellular and protein levels due to their unusual physicochemical properties (e.g. small size, high surface area to volume ratio, chemical composition, crystallinity, electronic properties, surface structure reactivity and functional groups, inorganic or organic coatings, solubility, shape, and aggregation behavior).

Metal (Nanoparticles) NPs, in particular, have received increasing interest due to their widespread medical, consumer, industrial, and military applications. However, as particle size decreases, some metalbased NPs are showing increased toxicity, even if the same material is relatively inert in its bulk form (e.g., $\mathrm{Ag}$, $\mathrm{Au}$, and $\mathrm{Cu}$ ).

NPs also interact with proteins and enzymes within mammalian cells and they can interfere with the antioxidant defense mechanism leading to Reactive Oxygen Species (ROS) generation, the initiation of an inflammatory response and perturbation and destruction of the mitochondria causing apoptosis or necrosis [13]. Furthermore,
NPs may induce oxidative stress and generate free radicals that could disrupt the endothelial cell membrane [14].

NPs with their small size and large surface area have been reported to interact with proteins [15] and enzymes within mammalian cells and to generate ROS. When the depletion of the antioxidant defense mechanism occurs and ROS accumulate, an inflammatory response can be initiated leading to the perturbation and destruction of the mitochondria resulting in eventual programmed cell death [16]. Other cellular level changes associated with current mechanisms of toxicity include decreases in GSH levels and an up-regulation of oxidative stress and inflammatory genes. Several studies with Ag NPs have demonstrated toxicity through an oxidative stress pathway $[17,18]$.

A Complete Blood Count ( $\mathrm{CBC}$ ) gives important information about kinds and numbers of cells in the blood, especially Red Blood Cells (RBCs), White Blood Cells (WBCs) and platelets. A CBC

*Corresponding author: Mohamed Anwar K Abdelhalim, Department of Physics and Astronomy, College of Science, King Saud University, P.O. 2455, Riyadh 11451, Saud Arabia, E-mail: abdelhalimmak@yahoo.com

Received March 19, 2012; Accepted May 23, 2012; Published May 28, 2012

Citation: Abdelhalim MAK, Moussa SAA (2012) The Dimensional Hematological Alterations Induced in Blood of Rats In vivo by Intraperitoneal Administration of Gold Nanoparticles. J Nanomed Nanotechol 3:138. doi:10.4172/2157-7439.1000138

Copyright: (c) 2012 Abdelhalim MAK, et al. This is an open-access article distributed under the terms of the Creative Commons Attribution License, which permits unrestricted use, distribution, and reproduction in any medium, provided the original author and source are credited. 
Citation: Abdelhalim MAK, Moussa SAA (2012) The Dimensional Hematological Alterations Induced in Blood of Rats In vivo by Intraperitoneal Administration of Gold Nanoparticles. J Nanomed Nanotechol 3:138. doi:10.4172/2157-7439.1000138

(Complete Blood Count) helps in diagnosing conditions, such as anemia, infection, and many other disorders. To quantify the toxicity of GNPs, the next important step is to assess the various hematological parameters such as Hematocrit (HCT), Hemoglobin (HB), Red Blood Cells (RBCs), White Blood Cells (WBCs) and Platelets (PLTs) counts. In medicine, there is limited knowledge on the dimensional hematological alterations induced by administration of (Gold Nanoparticles) GNPs. This study not only aimed to involve measurement of routine hematological indices but also to identify and interpret different dimensional hematological parameters to quantify the toxicity induced by intraperitoneal administration of different sizes of GNPs, which have not been documented and reported before.

\section{Materials and Methods}

\section{GNPs administration and preparation of blood}

A total of 30 healthy male Wistar-Kyoto rats were obtained from the Laboratory Animal Center (College of Pharmacy, King Saud University, Saudi Arabia).The rats nearly of the same age (12 weeks old) and weighing 220-240 g of King Saud University colony were used. Animals were randomly divided into groups, 2GNPs-treated rats groups and one Control Group (CG).

10 and $50 \mathrm{~nm}$ GNPs were intraperitonealy administered in rats at the rate of 3 days as follows: Group 1 received infusion of $50 \mu \mathrm{l} \mathrm{GNPs} \mathrm{of}$ size $10 \mathrm{~nm}$ for 3 days $(\mathrm{n}=10)$; Group 2 received infusion of $50 \mu \mathrm{l}$ GNPs of size $50 \mathrm{~nm}$ for 3 days $(\mathrm{n}=10)$. Control group received no GNPs $(\mathrm{n}=10)$. The rats were maintained on standard laboratory rodent diet pellets and housed in humidity and temperature-controlled ventilated cages on a $12 \mathrm{~h}$ day/night cycle.

The rats were anesthetized by inhalation of $5 \%$ isoflurane until muscular tonus relaxed. Blood sample of nearly $2 \mathrm{ml}$ was collected into 2 polypropylene tubes: the $1^{\text {st }}$ tube for serum and the $2^{\text {nd }}$ tube for whole blood. The serum was prepared by allowing the blood to clot at $37^{\circ} \mathrm{C}$ and then centrifuged at 3,000 rpm for ten minutes. The whole blood was collected in (Ethylenediaminetetraacetic acid) EDTA. All experiments were conducted in accordance with the guidelines approved by King Saud University Local Animal Care and Use Committee.

\section{Hematological analysis}

An hematological autoanalyzer (Orphee Mythic 22 Hematological Analyzer; Diamond Diagnostic; USA) was used to determine different hematological parameters, such as Red Blood Cells (RBC), White Blood Cells (WBCs), Hemoglobin (HB), Hematocrit (HCT), Mean Corpuscular Volume (MCV), Mean Corpuscular Hemoglobin (MCH), Mean Corpuscular Hemoglobin Concentration (MCHC), Red blood cell Distribution Width (RDW), neutrophils\%, lymphocytes\%, monocytes\%, eosinophils\%, basophils\%, Mean Platelet Volume (MPV), Platelet Distribution Width (PDW)\%, Plateletcrit (PCT)\% and Platelets (PLTs).

\section{Results and Discussion}

\section{Size and morphology of different GNPs}

Abdelhalim and Mady [19], have reported that in the (Transmission electron microscopy) TEM images, 10 and $20 \mathrm{~nm}$ GNPs showed spherical morphology while the $50 \mathrm{~nm}$ GNPs, in contrast, were not spherical but hexagonal in (Transmission electron microscopy) TEM images, as shown in Figure 1. The measured mean size was $9.45 \pm 1.33$ $\mathrm{nm}$ for $10 \mathrm{~nm}$ GNPs and $20.18 \pm 1.80 \mathrm{~nm}$ for $20 \mathrm{~nm}$ GNPs.
This study was not aimed to assess the short-term and long-term side effects of intraperitoneal administration of GNPs, but it aimed to show that the toxicity induced by GNPs might due to changes induced in different dimensional hematological parameters such as $\mathrm{MCV}$, $\mathrm{MCH}, \mathrm{MCHC}, \mathrm{MPV}, \mathrm{PCT} \%$ and PDW\%, and not only blood count. Moreover, this study demonstrates morphological and deformability changes in RBCs after intraperitoneal administration of GNPs.

The WBCs count decreased after intraperitoneal administration of 10 and $50 \mathrm{~nm}$ GNPs compared with the control, and WBCs count accompanied with the administration of $10 \mathrm{~nm}$ GNPs significantly decreased compared with $50 \mathrm{~nm}$ GNPs and control. The role of WBCs is protecting the body against the different infections. If an infection develops, WBCs attack and destroy the bacteria, virus, or other organism causing it. When an organism has a bacterial infection, the number of WBCs rises very quickly. The number of WBCs is sometimes used to see how the body is dealing with cancer treatment. The decrease in WBCs count indicating decrease in the immune system, and therefore the organism becomes susceptible to any infection or dangerous external agent (Table 1).

It has been reported that the $10 \mathrm{~nm}$ GNPs induced an increase in WBCs count, while the 5 and $30 \mathrm{~nm}$ GNPs induced a decrease in WBCs and RBCs counts. The biochemistry results show that the 10 and $60 \mathrm{~nm}$ (Polyethylene glycol) PEG-coated GNPs caused a significant increase in alanine transaminase and aspartate transaminase levels, indicating slight damage to the liver [7]. Recently, size-dependent organ distribution of GNPs has been investigated, and the results

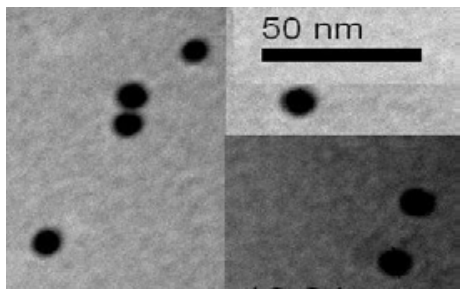

$10 \mathrm{~nm}$

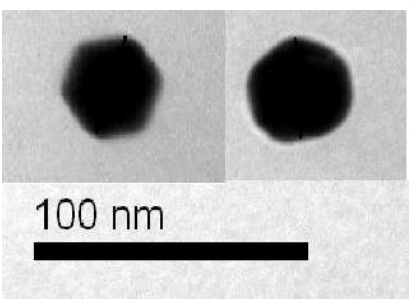

$50 \mathrm{~nm}$
Figure 1: TEM images for different GNP samples.

\begin{tabular}{|c|c|c|c|}
\hline Parameter & Control & $\begin{array}{c}\text { G1A } \\
(\mathbf{1 0} \mathbf{n m} \text { GNPs) }\end{array}$ & $\begin{array}{c}\text { G2A } \\
(\mathbf{5 0} \text { nm GNPs) }\end{array}$ \\
\hline $\begin{array}{c}\text { White blood cells (WBCs) } \\
\text { count }\end{array}$ & $6.69 \pm 0.98$ & $4.74 \pm 0.44^{*}$ & $6.46 \pm 0.65$ \\
\hline Lymphocytes \% & $71.18 \pm 2.13$ & $81.71 \pm 2.16^{*}$ & $74.09 \pm 1.69^{*}$ \\
\hline Monocytes \% & $3.49 \pm 0.32$ & $2.66 \pm 0.38^{*}$ & $3.44 \pm 0.6$ \\
\hline Neutrophils \% & $19 \pm 1.63$ & $11.76 \pm 1.8^{*}$ & $16.39 \pm 1.46^{*}$ \\
\hline Eosinophils \% & $1.6 \pm 0.22$ & $0.96 \pm 0.22^{*}$ & $0.87 \pm 0.21^{*}$ \\
\hline $\begin{array}{c}\text { Basophils \% } \\
\text { Red blood cells (RBCs) } \\
\text { count }\end{array}$ & $4.73 \pm 0.39$ & $2.89 \pm 0.35^{*}$ & $5.21 \pm 0.35$ \\
\hline Hemoglobin (HB) & $4.59 \pm 0.59$ & $5.62 \pm 0.97^{*}$ & $6.51 \pm 0.67$ \\
\hline $\begin{array}{c}\text { Mean corpuscular } \\
\text { hemoglobin (MCH) }\end{array}$ & $5.96 \pm 2.37$ & $10.61 \pm 3.72^{*}$ & $13.03 \pm 3.29^{*}$ \\
\hline $\begin{array}{c}\text { Mean corpuscular } \\
\text { hemoglobin concentration } \\
\text { (MCHC) }\end{array}$ & $15.49 \pm 3.2$ & $21.8 \pm 4.86^{*}$ & $24.54 \pm 4.44^{*}$ \\
\hline $\begin{array}{c}\text { Platelets (PLTs) or } \\
\text { thrombocytes count }\end{array}$ & $315.09 \pm 118.36$ & $629.81 \pm 207.9^{*}$ & $764.94 \pm 188.43^{*}$ \\
\hline
\end{tabular}

Table 1: Complete blood count after intraperitoneal administration of 10 and 50 nm GNPs in rats. 
showed that small GNPs of 5-15 $\mathrm{nm}$ had a wider organ distribution than that of larger GNPs of 50-100 nm, with the liver and spleen being the dominant targeted organs [20-23].

The lymphocytes\% accompanied with administration of $10 \mathrm{~nm}$ GNPs significantly increased compared with $50 \mathrm{~nm}$ GNPs and control (Table 1). The lymphocytes represent the first defense line against the different infections in the body. It has been reported that $10 \mathrm{~nm}$ GNPs directly interacts with the lymphocyte [24]. This can confirm the usefulness of GNPs as a novel drug delivery system to the lymphocyte [25].

A decrease in the majority of monocytes\%, neutrophils\%, eosinophils\% and basophils\% after intraperitoneal administration of 10 and $50 \mathrm{~nm}$ GNPs compared with the control, and monocytes\%, neutrophils\%, eosinophils\% and basophils\% accompanied with administration of $10 \mathrm{~nm}$ GNPs significantly decreased compared with $50 \mathrm{~nm}$ GNPs and control (Table 1). The major types of WBCs (White Blood Cells) are neutrophils, lymphocytes, monocytes, eosinophils, and basophils. Each type of cell plays a different role in protecting the body. The numbers of each type gives important information about the immune system. Too many or too few of the different types can indicate an infection, allergic or toxic reaction to medicines or chemicals, and many conditions, such as leukemia.

In this study, RBCs count shows a decrease after intraperitoneal administration of 10 and $50 \mathrm{~nm}$ GNPs compared with the control. The RBCs count accompanied with administration of $10 \mathrm{~nm}$ GNPs significantly decreased compared with $50 \mathrm{~nm}$ GNPs and control indicating the occurrence of anemia and hypoxia (Table 1). The decrease in RBCs (anemia) count means increased destruction of (Red Blood Cells) RBCs or lyses of (Red Blood Cells) RBCs. Lack of iron, vitamin $\mathrm{B} 12$, or folic acid in the diet, as well as certain chronic diseases, lower the number of red blood cells produced by the bone marrow. Zhang XD et al. [26], deduced the same trend for RBCs count and also proved that the oral and intraperitoneal routes showed the highest toxicity.

The RBCs are derived from hemopoietic stem cells in bone marrow. Following a series of maturation steps, directed mainly by erythropoietin, red cells enucleate and enter the circulatory system. Thus, the variation in RBCs count might be related to the hematopoietic system. It has been reported that GNPs induce an inflammatory response and increase or decrease in the activity of the immune system and alter the related hematologic factors such as blood cell counts $[27,28]$.

An increase in the HB level (Table 1) and HCT\% (Figure 2) after intraperitoneal administration of 10 and $50 \mathrm{~nm}$ GNPs compared with the control, respectively, and the HBlevel and HCT\% accompanied with administration of $50 \mathrm{~nm}$ GNPs significantly increased compared with $10 \mathrm{~nm}$ GNPs and control. The HCT\% measures the amount of RBCs volume taken up in the blood. The value is given as a percentage of RBCs in a volume of whole blood. The increase in HCT\% means an increase in RBCs volume, which in turn leads to lyses of RBCs. The HCT\% and HB level are the two major values that indicate if anemia or polycythemia is present.

Figure 2 shows the hematocrit (HCT) percent or packed cell volume in rats after intraperitoneal administration of 10 and $50 \mathrm{~nm}$ GNPs compared with the control

The relationships between the HCT, the HG level, and the RBCs are converted to red blood cell indices through mathematical formulas. The indices include MCV, MCH, MCHC and RDW. Figure 3 shows significant increase in MCV after intraperitoneal administration of 10 and $50 \mathrm{~nm}$ GNPs compared with the control, respectively. The MCV accompanied with the administration of $50 \mathrm{~nm}$ GNPs significantly increased compared with $10 \mathrm{~nm}$ GNPs and control. The MCV shows the size of RBCs. The increase in size of RBCs indicates changes in morphology and deformability of RBCs, which confirmed by slightly increase in the Red cell Distribution Width (RDW) \% (Figure 4).

A significant increase in $\mathrm{MCH}$ and $\mathrm{MCHC}$ after intraperitoneal administration of 10 and $50 \mathrm{~nm}$ GNPs compared with the control observed, respectively. The $\mathrm{MCH}$ and $\mathrm{MCHC}$ accompanied with administration of $50 \mathrm{~nm}$ GNPs significantly increased compared with $10 \mathrm{~nm}$ GNPs and control (Table 1).

Platelets (PLTs) or thrombocytes are the smallest type of blood cells and play an important role in blood clotting. When bleeding occurs, the PLTs swell, clump together, and form a sticky plug that helps stopping the bleeding. The PLTs count increased after intraperitoneal administration of 10 and $50 \mathrm{~nm}$ GNPs compared with the control, and the PLTs count accompanied with administration of $50 \mathrm{~nm}$ GNPs significantly increased compared with $10 \mathrm{~nm}$ GNPs and control (Table 1). The significant increase in PLTs count after administration of GNPs might lead to thrombosis or aggregation inside the blood vessels (vein or artery) and promoting the progression of atherosclerosis which is

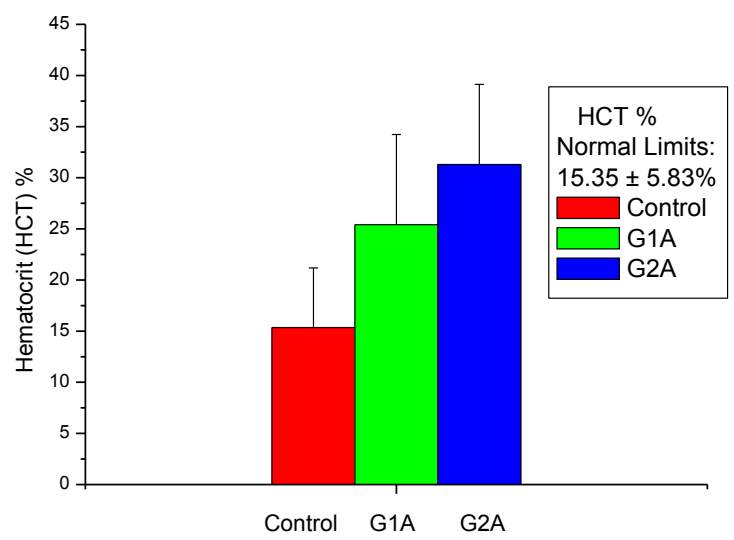

Figure 2: Hematocrit $(\mathrm{HCT})$ percent or packed cell volume in rats after intraperitoneal administration of 10 and $50 \mathrm{~nm}$ GNPs compared with the control.

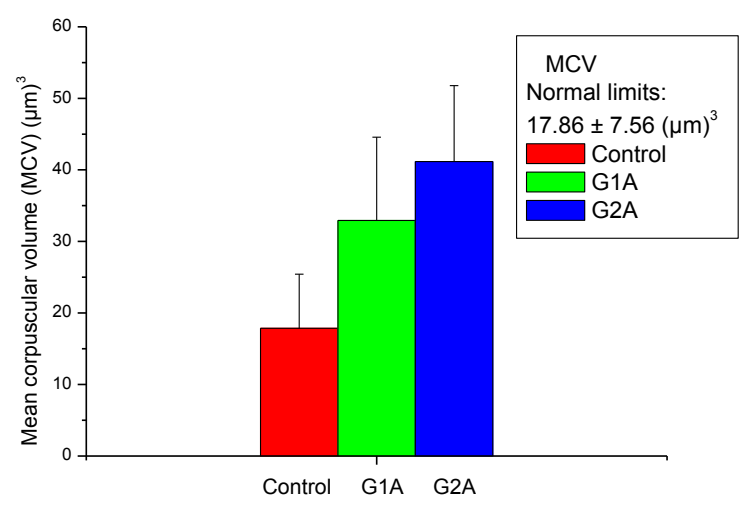

Figure 3: Mean Corpuscular Volume (MCV) in rats after intraperitonea administration of 10 and $50 \mathrm{~nm}$ GNPs compared with the control. 
considered the most dangerous toxicity induced by administration of GNPs.

Figure 5, Figure 6 and Figure 7 show a decrease in MPV, PCT\% and PDW\% after intraperitoneal administration of 10 and $50 \mathrm{~nm}$ GNPs compared with the control. The MPV, PCT\% and PDW\% accompanied with administration of $50 \mathrm{~nm}$ GNPs significantly decreased compared with $10 \mathrm{~nm}$ GNPs and control. The MPV describes the average size of PLTs cells in the blood and provides whether the bone marrow manufactures PLTs normally or not. The significant decrease in MPV indicates the disturbance induced in the bone marrow manufacturing the PLTs.

Abdelhalim MA [29], has reported that as GNP size increases, e.g. decease in the number of NPs, the blood absorbance decreases and shifts towards the UV. In addition, absorbance is particle size and exposure duration dependent. GNPs absorbed within the systemic circulation can be excreted through various routes. One possible elimination route for GNPs could be renal and biliary clearance. Renal clearance of solid nano-sized materials was affected by particle size and surface charge.

Various papers regarding the histopathological changes in various rat organs have been reported by Abdelhalim [30-35]. Abdelhalim and Jarrar have published several articles related to the histological alterations in several rat organs, and indicated that the amount of accumulated GNPs in the organ reflected the toxicity. These histological

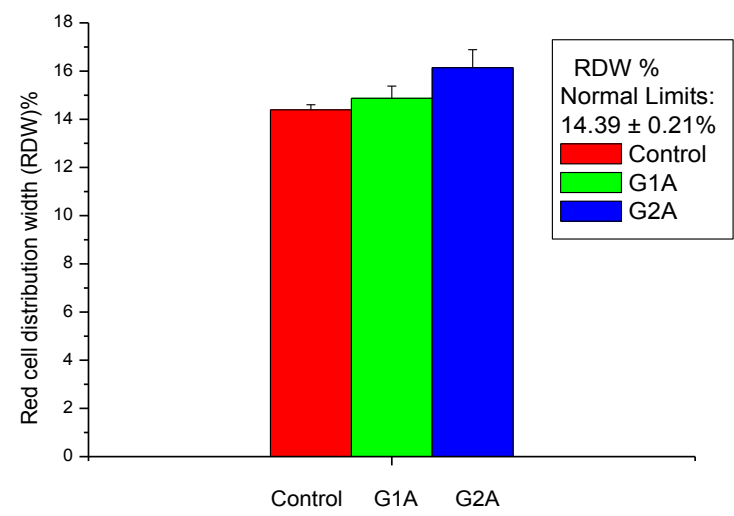

Figure 4: Red cell Distribution Width (RDW) \% in rats injected after intraperitoneal administration of 10 and $50 \mathrm{~nm}$ GNPs compared with the control.

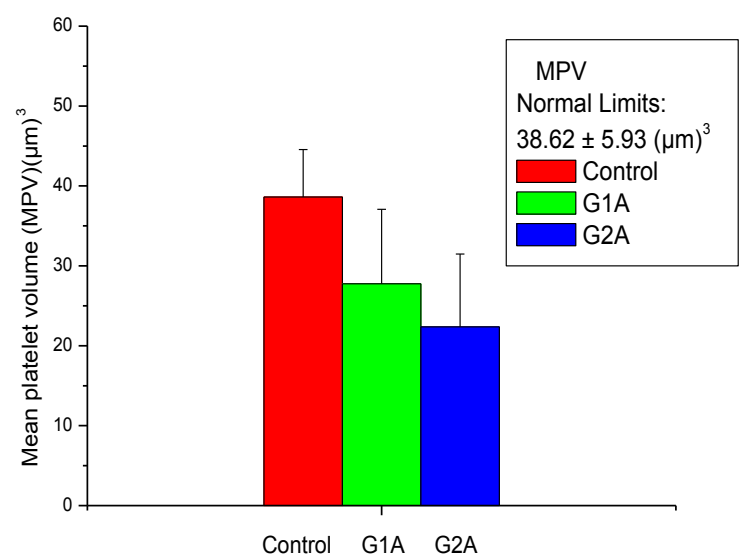

Figure 5: Mean Platelet Volume (MPV) in rats after intraperitoneal administration of 10 and $50 \mathrm{~nm}$ GNPs compared with the control.

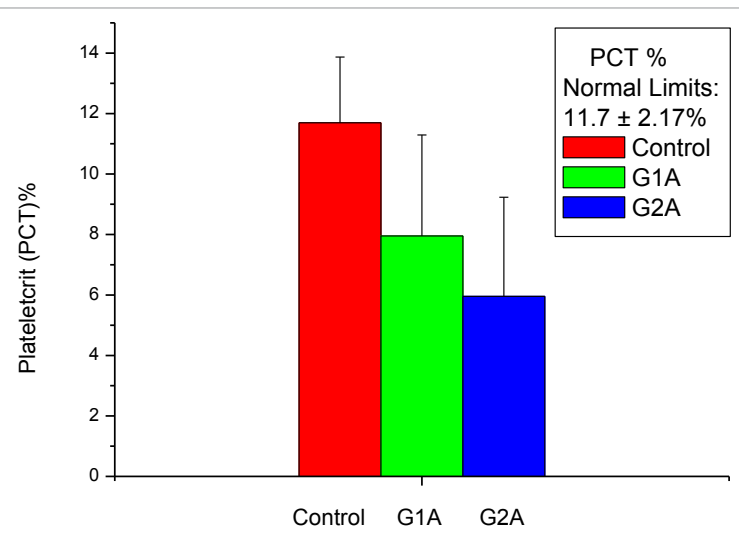

Figure 6: Platelet percent in rats after intraperitoneal administration of 10 and $50 \mathrm{~nm}$ GNPs compared with the control.

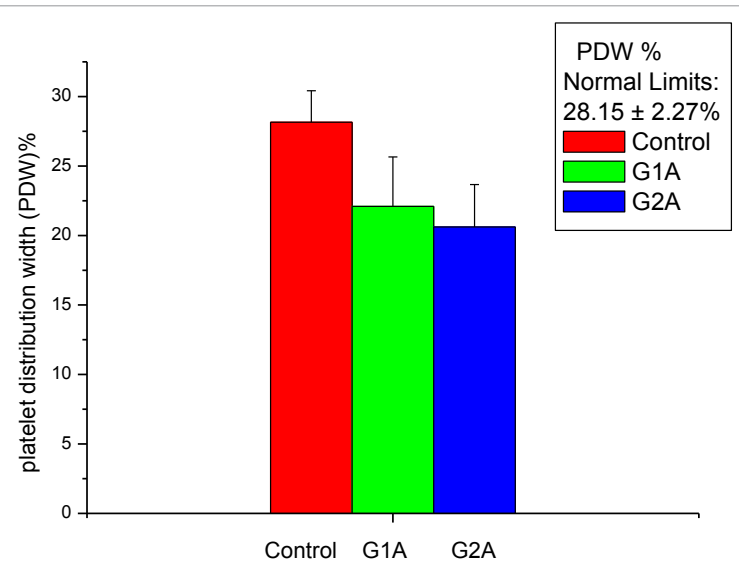

Figure 7: Platelet distribution width percent (PDW) \% in rats after intraperitoneal administration of 10 and $50 \mathrm{~nm}$ GNPs compared with the control.

alterations were size-dependent with smaller ones induced the most effects and related with time exposure of GNPs.

The administration of GNPs induced in the liver: prominent inflammatory, central vein intima disruption, fatty change and Kupffer cells hyperplasia, cloudy swelling to hydropic degeneration, cytoplasmic hyaline vacuolation, polymorphism, binucleation, karyopyknosis, karyolysis, karyorrhexis and necrosis [30,31]; in the kidney organ: renal cells cytoplasmic degeneration and nuclear destruction [32,33]; in the heart organ: disarray of heart muscle, hemorrhagic, chronic inflammatory cells infiltrated by small lymphocytes, cytoplasmic vacuolization and congested and dilated blood vessels, cardiac organ damage [34,35]; in the lung organ: pneumonia, fibrosis, chronic inflammatory cell infiltrates, congested and dilated blood vessels, and hemosiderin granule and emphysema foci [36].

This study suggests that additional experiments will be performed taking in consideration the morphology and deformability changes of RBCs using the Transmission Electron Microscopy (TEM) as well as other physical techniques.

\section{Conclusions}

A total of 30 healthy male Wistar-Kyoto rats were used in this study. Animals were randomly divided into 2 GNPs-treated G1 and 
Citation: Abdelhalim MAK, Moussa SAA (2012) The Dimensional Hematological Alterations Induced in Blood of Rats In vivo by Intraperitoneal Administration of Gold Nanoparticles. J Nanomed Nanotechol 3:138. doi:10.4172/2157-7439.1000138

G2; received intraperitoneal administration of $50 \mu \mathrm{l}$ of 10 and $50 \mathrm{~nm}$ GNPs for a period of 3 days.

After intraperitoneal administration of GNPs for period of 3 days, the results can be summarized as follows:

A decrease in WBCs count might indicate a disturbance in the function of immune system efficiency.

A decrease in RBCs count might due to increased loss or destruction of RBCs, due to the lyses of RBCs and defect induced in hematopoietic stem cells of the bone marrow, which confirmed by an increase in hematocrit\% and RBCs volume.

The increase in RBCs size indicates changes in morphology and deformability of RBCs, which confirmed by a slightly increase in the Red cell Distribution Width (RDW)\%.

The significant increase in PLTs count might lead to thrombosis or aggregation in the blood vessels and promoting the progression of atherosclerosis which is considered the most dangerous toxicity induced by administration of GNPs.

The significant decrease in MPV might due to disturbance induced in the bone marrow manufacturing the PLTs. On the other hand, the MPV can be considered a more subtle type of measurement than a simple PLTs count.

\section{Acknowledgements}

The authors are very grateful to National Plan of Science of Technology (NPST). This research was financially supported by the National Science and Technology Innovation Plan (NSTIP), Research No. 08-ADV206-02 and Research No. 09-NAN670-02, College of Science, King Saud University, Saudi Arabia.

\section{References}

1. Huang X, Jain PK, El-Sayed IH, El-Sayed MA (2007) Gold nanoparticles: interesting optical properties and recent applications in cancer diagnostics and therapy. Nanomedicine (Lond) 2: 681-693.

2. Han G, Ghosh P, Rotello VM (2007) Functionalized gold nanoparticles for drug delivery. Nanomedicine 2: 113-123.

3. Thaxton CS, Rosi NL, Mirkin CA (2005) Optically and chemically encoded nanoparticle materials for DNA and protein detection. MRS Bull 30: 376-380.

4. El-Sayed IH, Huang X, El-Sayed MA (2005) Surface plasmon resonance scattering and absorption of anti-EGFR antibody conjugated gold nanoparticles in cancer diagnostics: applications in oral cancer. Nano Lett 5: 829-834.

5. Storhoff JJ, Mirkin CA (1999) Programmed materials synthesis with DNA Chem Rev 99: 1849-1862.

6. Yi H, Leunissen J, Shi G, Gutekunst C, Hersch S (2001) A novel procedure for pre-embedding double immunogold-silver labeling at the ultrastructural level. $J$ Histochem Cytochem 49: 279-284.

7. Voskerician G, Shive MS, Shawgo RS, von Recum H, Anderson JM, et al. (2003) Biocompatibility and biofouling of MEMS drug delivery devices. Biomaterials 24: 1959-1967.

8. Sharma P, Brown SC, Bengtsson N, Zhang Q, Walter GA, et al. (2008) Goldspeckled multimodal nanoparticles for noninvasive. Chem Mater 20: 60876094.

9. Hirsch LR, Stafford RJ, Bankson JA, Sershen SR, Rivera B, et al. (2003) Nanoshell-mediated near-infrared thermal therapy of tumors under magnetic resonance guidance. Proc Natl Acad Sci U S A 100: 13549-13554.

10. Loo C, Lin A, Hirsch L, Lee MH, Barton J, et al. (2004) Nanoshell-enabled photonics-based imaging and therapy of cancer. Technol Cancer Res Treat 3: $33-40$

11. Hainfeld JF, Slatkin DN, Smilowitz HM (2004) The use of gold nanoparticles to enhance radiotherapy in mice. Phys Med Biol 49: N309-N315.
12. Pissuwan D, Valenzuela SM, Killingsworth MC, Xu X, Cortie MB (2007) Targeted destruction of murine macrophage cells with bioconjugated gold nanorods. J Nanopart Res 9: 1109-1124.

13. Schrand AM, Rahman MF, Hussain SM, Schlager JJ, Smith DA, et al. (2010) Metal-based nanoparticles and their toxicity assessment. Wiley Interdiscip Rev Nanomed Nanobiotechnol 2: 544-568.

14. Sharma HS, Sharma A (2007) Nanoparticles aggravate heat stress induced cognitive deficits, blood-brain barrier disruption, edema formation and brain pathology. Prog Brain Res 162: 245-273.

15. You C, De M, Rotello VM (2005) Monolayer-protected nanoparticle-protein interactions. Curr Opin Chem Biol 9: 639-646.

16. Chen X, Schluesener HJ (2008) Nanosilver: a nanoproduct in medical application. Toxicol Lett 176: 1-12.

17. Hussain SM, Hess KL, Gearhart JM, Geiss KT, Schlager JJ (2005) In vitro toxicity of nanoparticles in BRL-3A rat liver cells. Toxicol in Vitro 19: 975-983.

18. Schrand AM, Bradich-Stolle LK, Schlager JJ, Dai L, Hussain SM (2008) Can silver nanoparticles be useful as potential biological labels? Nanotechnology 19: 1-13.

19. Abdelhalim MAK, Mady MM (2011) Liver uptake of gold nanoparticles after intraperitoneal administration in vivo: A fluorescence study. Lipids Health Dis 10: 195

20. Zhang XD, Wu D, Shen X, Liu PX, Yang N, et al. (2011) Size-dependent in vivo toxicity of PEG-coated gold nanoparticles. Int J Nanomedicine 6: 2071-2081.

21. De Jong WH, Hagens WI, Krystek P, Burger MC, Sips AJ, et al. (2008) Particle size-dependent organ distribution of gold nanoparticles after intravenous administration. Biomaterials 29: 1912-1919.

22. Sonavane G, Tomoda K, Makino K (2008) Biodistribution of colloidal gold nanoparticles after intravenous administration: effect of particle size. Colloids Surf B Biointerfaces 66: 274-280.

23. Chen YS, Hung YC, Liau I, Huang GS (2009) Assessment of the in vivo toxicity of gold nanoparticles. Nanoscale Res Lett 4: 858-864.

24. Wiwanitkit V, Sereemaspun A, Rojanathanesm R (2009) Identification of gold nanoparticle in lymphocytes: a confirmation of direct intracellular penetration effect. Turk J Hematol 26: 29-30.

25. Fahmy TM, Fong PM, Park J, Constable T, Saltzman WM (2007) Nanosystems for simultaneous imaging and drug delivery to T cells. AAPS J 9: E171-E180.

26. Zhang XD, Wu HY, Wu D, Wang YY, Chang JH, et al. (2010) Toxicological effects of gold nanoparticles in vivo by different administration routes. Int $J$ Nanomedicine5: 771-781.

27. Gjetting T, Arildsen NS, Christensen CL, Poulsen TT, et al. (2010) In vitro and in vivo effects of polyethylene glycol (PEG)-modified lipid in DOTAP/ cholestero mediated gene transfection. Int J Nanomedicine 5: 371-383.

28. Hauck TS, Anderson RE, Fischer HC, Newbigging S, Chan WC (2010) In vivo quantum-dot toxicity assessment. Small 6: 138-144.

29. Abdelhalim MA (2012) The bioaccumulation and toxicity induced by gold nanoparticles in rats in vivo can be detected by ultraviolet-visible (UV-visible) spectroscopy. African Journal of Biotechnology 11: 9399-9406.

30. Abdelhalim MA, Jarrar BM (2011) Gold nanoparticles administration induced prominent inflammatory, central vein intima disruption, fatty change and Kupffer cells hyperplasia. Lipids Health Dis 10: 133.

31. Abdelhalim MA, Jarrar BM (2011) Gold nanoparticles induced cloudy swelling to hydropic degeneration, cytoplasmic hyaline vacuolation, polymorphism, binucleation, karyopyknosis, karyolysis, karyorrhexis and necrosis in the liver Lipids Health Dis 10: 166.

32. Abdelhalim MA, Jarrar BM (2011) The appearance of renal cells cytoplasmic degeneration and nuclear destruction might be an indication of GNPs toxicity. Lipids Health Dis 10: 147

33. Abdelhalim MA, Jarrar BM (2011) Renal tissue alterations were size-dependen with smaller ones induced more effects and related with time exposure of gold nanoparticles. Lipids Health Dis 10: 163.

34. Abdelhalim MA (2011) Exposure to gold nanoparticles produces cardiac tissue damage that depends on the size and duration of exposure. Lipids Health Dis 10: 205 
Citation: Abdelhalim MAK, Moussa SAA (2012) The Dimensional Hematological Alterations Induced in Blood of Rats In vivo by Intraperitoneal Administration of Gold Nanoparticles. J Nanomed Nanotechol 3:138. doi:10.4172/2157-7439.1000138

Page 6 of 6

35. Abdelhalim MA (2011) Gold nanoparticles administration induces disarray of heart muscle, hemorrhagic, chronic inflammatory cells infiltrated by smal lymphocytes, cytoplasmic vacuolization and congested and dilated blood vessels. Lipids Health Dis 10: 233.
36. Abdelhalim MA (2012) Exposure to gold nanoparticles produces pneumonia fibrosis, chronic inflammatory cell infiltrates, congested and dilated blood vessels, and hemosiderin granule and emphysema foci. Journal of Cancer Science \& Therapy 4: 46-50. 